\title{
Epidemiology of hip fractures in Zanjan, Iran
}

\author{
Majid Valizadeh • Saeideh Mazloomzadeh • Robab Azizi
}

Received: 14 April 2008 / Accepted: 5 June 2008 / Published online: 8 August 2008

(C) The Author(s) 2008

\begin{abstract}
Summary The aim of this study was to estimate the incidence of hip fracture in Zanjan, Iran and to describe its seasonal variation. A total of 244 cases of hip fractures (131 men, 113 women) were recorded during 1 year. The annual age-standardized incidence rates were 206.5 and 214.8 per 100,000 men and women, respectively. Most fractures occurred in winter, in-house and daytime. In-hospital mortality was $2.5 \%$. Incidence rate of hip fracture (HF) was less than in western countries mostly due to lower incidence in women, which is probably because of breast-feeding.

Introduction One of the most important consequences of osteoporosis is HF, which causes high mortality, morbidity, and significant costs. The incidence of HF in the elderly varies in different areas. Various incidence rates of HF have been reported from countries in the Middle East. The aim of this prospective study was to estimate the annual incidence of hip fracture in Zanjan, a province of Iran, and to describe the seasonal variation of HF incidence which has not been evaluated in two previous studies conducted in this country. Materials and methods All cases of HF aged 50 years or more admitted in three referral hospitals with orthopedics
\end{abstract}

M. Valizadeh $(\bowtie)$

Department of Internal Medicine, Vali e Asar Hospital,

Zanjan University of Medical Science,

Zanjan, Iran

e-mail: mvalizadeh47@yahoo.com

S. Mazloomzadeh

Department of Social Medicine,

Zanjan University of Medical Sciences,

Zanjan, Iran

R. Azizi

Health Center,

Zanjan, Iran facilities in Zanjan province between 21 March 2006 and 20 March 2007 were subjected in the study. The age- and sex-specific incidence rates of hip fracture per 100,000 person-years were calculated using the population data from the last national census in Iran 2007.

Results A total of 244 cases of hip fractures (131 men, 113 women) were recorded. The annual age-standardized incidence rate was 214.8 per 100,000 women and 206.5 per 100,000 men. The number (\%) of fall-induced HF was $88(67.2 \%)$ in men and $102(90.3 \%)$ in women. The female to male ratio for total and fall-related HF was 1.0 and 1.1, respectively. The HF was more predominant in winter (38.5\%). In-hospital mortality was $2.5 \%$, and majority of HF were sustained in-house and daytime.

Conclusion We found a relatively low incidence of hip fracture and fall-related hip fracture in Iran than those in western countries, which is mostly due to the lower rate in women. These findings disagree with our expectations considering the bone mineral density and vitamin D status of Iranian population, especially women. Breastfeeding could be one of the probable protective factors.

Keywords Hip fracture · Incidence · Iran · Osteoporosis · Zanjan

\section{Introduction}

One of the most important consequences of osteoporosis is hip fracture (HF), which causes high mortality, morbidity, and significant costs. The incidence of hip fracture in the elderly varies in different area of the world. For instance, it is highest in the USA and lowest in Africa. Indeed, understanding the epidemiology of HF could provide basic information in defining the burden of illness and planning 
Table 1 Annual age- and sex-specific incidence rates (per 100,000) of hip fracture

\begin{tabular}{lcccccrccc}
\hline Age group & Male number & Population & Rate & \multicolumn{1}{c}{$95 \%$ CI } & Female number & Population & Rate & $95 \%$ CI & F/M ratio \\
\hline $50-59$ & 16 & 27,990 & 57.2 & $29.2-85.2$ & 8 & 32,262 & 24.8 & $7.4-42.2$ & 0.4 \\
$60-69$ & 25 & 19,580 & 127.7 & $77.6-177.8$ & 23 & 20,242 & 113.6 & $67.2-160.0$ & 0.9 \\
$70-79$ & 56 & 15,380 & 364.1 & $268.9-459.3$ & 30 & 12,985 & 231.0 & $148.7-313.3$ & 0.6 \\
$\geq 80$ & 34 & 5,677 & 598.9 & $396.5-801.3$ & 52 & 4,993 & 1041.5 & $758.0-1325.0$ & 1.7 \\
Total & 131 & 68,627 & 190.9 & $158.1-223.7$ & 113 & 70,482 & 160.3 & $130.7-189.9$ & 0.8 \\
\hline
\end{tabular}

for preventive strategies for osteoporosis. Despite numerous studies that have been published on the epidemiology of hip fracture in developed countries [1-5], this issue has been poorly understood in developing countries.

The results of a few previous studies carried out in the Middle East show various incidence for hip fracture in this area [6-8]. To our knowledge, only two studies have been published on the epidemiology of HF in Iran [6, 7]. The most recent study reported a low rate for $\mathrm{HF}$ incidence in Iran than those in Western countries. Although this study has covered a larger area across the country (nine provinces), it was carried out on warm season of the year and had a short duration (4.5 months). Thus, the possibility of underestimation in incidence rates cannot be ruled out.

The aim of this prospective study was to determine the annual incidence of hip fractures in patients 50 years of age and older in Zanjan province of Iran. We also described ageand sex-specific incidence rates of low trauma (fall-induced) fracture, seasonal variation, and in-hospital mortality.

\section{Materials and methods}

Zanjan province is located in the northwest region of Iran almost $300 \mathrm{~km}$ far from Tehran. Its latitude is $36.41^{\circ} \mathrm{N}$ and has a Mediterranean climate characterized by cold snowy weather in the mountains and moderate climate in the plains in wintertime. In the summers, the weather is warm. Based on the national census in 2007, the province has 964,601 habitants, $14.4 \%$ of which is 50 years old and over.

Zanjan has three referral hospitals with orthopedic facilities. We collected our data from these hospitals. All cases of HF aged 50 years or more admitted in these hospitals between 21 March 2006 and 20 March 2007 were included in the study. A daily surveillance was performed for all the orthopedic units and each admitted case of hip fracture investigated carefully by a trained research assistant. Fractures were classified as: (1) the proximal femur (i.e., those occurring above the level of the lesser trochanter), (2) cervical, (3) intertrochanteric, and (4) greater trochanter. Patients, or a family member, were interviewed to collect information in regards to the past medical history, time and place of the fracture occurrences. Patients' outcome (death in hospital or discharge) was also determined.
The age- and sex-specific incidence rates of hip fracture per 100,000 person-years were calculated by dividing the number of hip fractures during the study period by the number of persons who were equal or more than 50 years old during that period. The population data were obtained from the last national census in 2007 provided by the Iranian Statistical Center, the branch of the management and planning organization. The age-specific rates in men and women aged $\geq 50$ years were then applied to the 2000 US population to calculate age-adjusted rates of hip fracture. For this purpose, the direct method of standardization was used. Usual statistical procedures ( $t$ test) were applied as appropriate.

\section{Results}

A total number of 244 new cases of hip fracture (131 men, 113 women) occurred in people aged $\geq 50$ years during the study period. The mean age $( \pm \mathrm{SD})$ of patients was $73.9 \pm$ 11.1. The mean age $( \pm \mathrm{SD})$ for men and women were $72.0 \pm$ 10.6 and $76.0 \pm 11.4(P=0.005)$, respectively. The age- and sex-specific incidence rates and female to male ratio of hip fractures were presented in Table 1. The crude annual incidence rate was 190.9 in men and 160.3 in women. In both sexes, the rates dramatically increased with increasing age. The incidence rates were lower in women than men up to age 80 , where it became almost double in women (Fig. 1). The annual age-standardized incidence rates were 206.5 per 100,000 men and 214.8 per 100,000 women. The female to

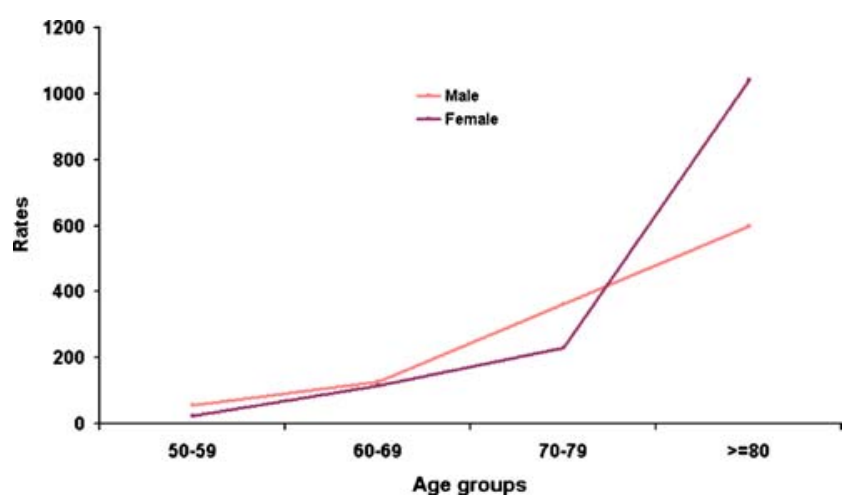

Fig. 1 Incidence rates of hip fractures by age groups 
Fig. 2 Seasonal variations of incidence of hip fracture

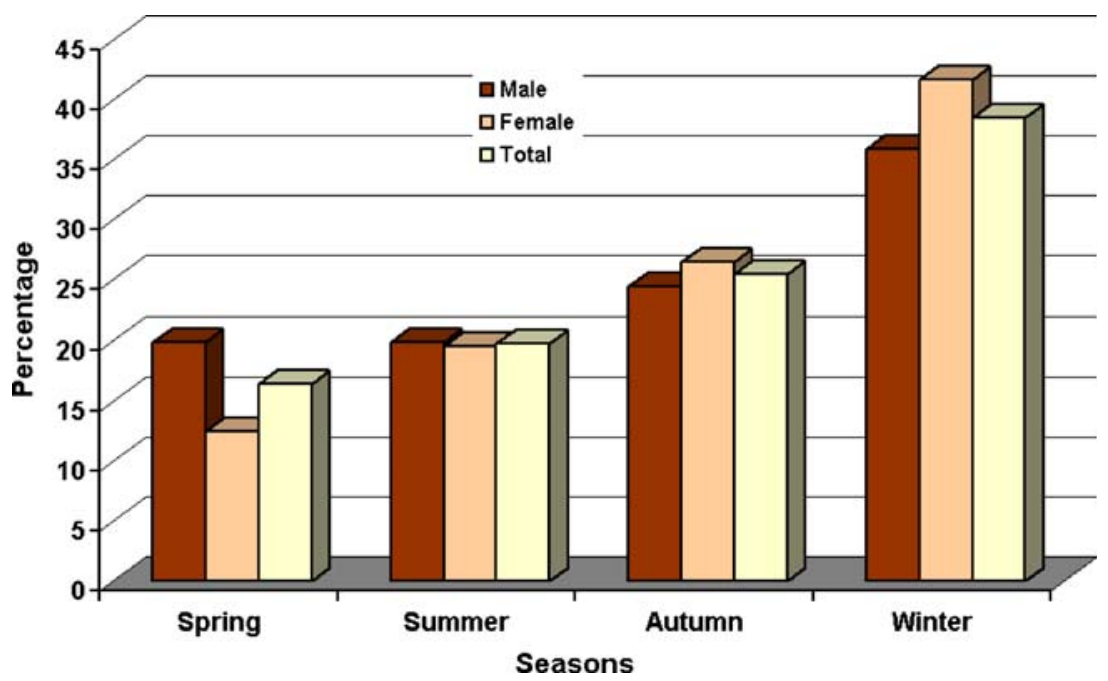

male ratio of hip fracture incidence was 1.0. The highest incidence of HF occurred in winter $(38.5 \%)$, with the lowest incidence in spring (16.4\%; Fig. 2). A similar pattern was observed for both sexes.

In 54 cases $(22.1 \%)$, fracture was appropriate with trauma intensity; however, $190(77.9 \%)$ had low-trauma (fall-induced) fracture. In low-trauma fracture group, 102 $(53.7 \%)$ and $88(46.3 \%)$ cases were women and men, respectively (female/male ratio, 1.1$)$. The mean age $( \pm \mathrm{SD})$ in this group was $75.9 \pm 10.3$ (range, 50-113). The mean age $( \pm \mathrm{SD})$ was $74.5 \pm 9.3$ for men and $77.1 \pm 11.0$ for women $(P=0.09)$. The highest frequency of low-trauma hip fracture was observed in both men and women aged $\geq 80$ years; however, in this age group, the fall-induced rate in women was two times greater than men (Fig. 3). Most of low-trauma fractures were sustained in house $(56.2 \%)$ and in daytime (85.1\%). In-hospital mortality in patients with $\mathrm{HF}$ during study period was $2.5 \%$ (six cases: four men and two women). All deaths occurred in patients aged $\geq 75$ years, and half of them were observed in winter.

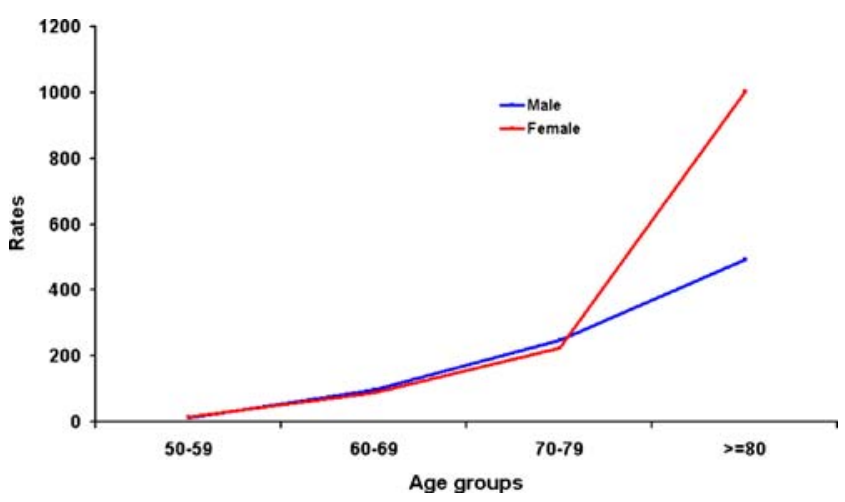

Fig. 3 Incidence rates of low-trauma hip fracture by age groups

\section{Discussion}

In this study, the standardized incidence rates of hip fracture were 206.5 and 214.8 per 100,000 men and women, respectively. The rates in both sexes were more than those reported by the previous study in Iran [6]. This difference may be due to the duration of that study. Moayyeri and his colleagues collected data in a limited timeframe and did not consider the effect of seasonal variation on the incidence of hip fracture. We found that HF is more frequent in winter.

Although the incidence rate of hip fracture in the present study was more than the latest study in Iran, it was lower than in western countries. Hip fracture has two main causes: low bone mineral density (BMD), which is an index for bone strength, and the falling. Low BMD has been known as an important risk factor for hip fracture in the elderly. So far, there is no evidence indicating that Iranian people have a higher BMD compared to population living in western countries. Importantly, results of studies carried out in Tehran (Iranian capital) and in many Iranian large cities on BMD have indicated that this index in Iran is slightly lower than it is in developing countries $[9,10]$. The other risk factor for osteoporotic fracture is propensity to fall. With respect to the high prevalence of vitamin D deficiency in Iran [11] and lower BMD, the probability of falling and hip fracture is expected to be high. However, the low rate of hip fracture in both our and the previous study is unexpected.

One possibility to explain the observed low HF incidence in Iran due to the low risk for falling could be that the majority of the elderly people in Iran live with their relatives. This means that they take the advantages of better care that causes less mobility in their daily life, leading to the reduction of the falling possibility. Besides, In Iran, most of elder populations spend most of their time at home; 
thus, they engage in social and recreational activities less. In contrast to Iran, in developed countries, most elder individuals live alone and apart from their family members. They have to be mobile to meet the daily requirements and take part in different social activities, which boosts the falling rate causing $\mathrm{HF}$.

The second possibility to explain the low HF incidence in Iran due to the low risk for falling is application of carpet for decoration on the floor in Iran. Decoration of floor with carpet is one of Iranian traditions that could markedly reduce the risk of a fall accident at home. Besides, a carpet is able to reduce the traumatic forces that result from falling, which reduces the effect of falling on the limb. In contrast to Iran, in western countries, floors are made of wood and tiles [12-14].

The bone geometric factors, for example shorter hip axis length, have been suggested to be an independent factor contributing to the lower incidence of fracture in some Asian countries [15]. This may be considered as a reason for the low observation of HF incidence in Iran; however, so far, no comparative investigation has been carried out on this factor in Iran. Thus, this issue remains as a matter of further dispute.

The results of this study have shown that the female to male ratio of hip fracture incidence was less than 1.0 for all age groups except $\geq 80$. The female to male ratio of the annual age-standardized incidence rate (1.0) was also lower than that reported in most western countries [5,16-18]; however, it was similar to the areas with low incidence rates of hip fracture in Asia, such as rural areas in Turkey [19] and Beijing in China [20]. The complete etiology of HF in these areas is not well understood [19-22].

Majority of differences in the ratio observed in this study is related to lower incidence in women, but the rate of hip fracture in Iranian men resembles those recorded in most western countries. A previous study in Iran showed similar results about the sex ratio [6]. This finding is not consistent with the lower bone density demonstrated in Iranian women than in men $[9,10]$. This is why we proposed that the risk of falling in women in our region may be less than in men. One study carried out in our country suggested that the incidence of fall injuries in men was higher than in women in age groups less than 60 years. After this age, however, the incidence rates showed a dramatic increase in women than in men. That study could not explain why shift in hip fracture incidence occurs after the age of 80 [23]. Interestingly, the results of some studies suggest that breast-feeding may reduce the risk of hip fractures in elderly women. These studies reported a dose-response relationship between the average duration of breast-feeding per child and the risk of hip fracture [24-27]. Bearing in mind that the majority of our female patients had a history of breast-feeding $(86.8 \%)$, protective effect of breast- feeding can partly explain the lower rate of hip fracture in our population.

We demonstrated lower incidences of HF in spring and summer than in autumn and winter. Some studies point to cold climate as a possible reason for the increase in winter fractures, perhaps related to shorter daylight time, lower exposure to sunlight, and synthesis of vitamin D or frozen ground [28-32]; however, in our study, most of hip fractures occurred in house and in daytime.

The lower in-hospital mortality for patients with HF in our study $(2.5 \%)$ compared to that of international level (4-12\%) [33] may be attributable to the lower age of our patients, which provides lower comorbidity.

Under-registration of HF cases is one of the major concerns in epidemiological studies based on data collection from hospitals. HF patients almost never stay home. Before registration in other centers for surgery, patients should be referred to our hospitals. Thus, the risk of underregistration of cases could not provide an impact on the results of our study. To our knowledge, this is the first prospective study with appropriate duration on HF incident carried out in Iran. The results of this study at least could be extended to other provinces with a similar climate.

In summary, we found a relatively low incidence of hip fracture and fall-related hip fracture in Iran than in those which has been reported in western countries, which is mostly due to lower rate in female. These findings disagree with our expectations considering the bone mineral density and vitamin D status of Iranian population especially for women. This may be due to several indirect factors including family support, life habit, carpet flooring, and breast-feeding and bone geometric factors. To evaluate the effect of indirect factors on the incidence of HF in Iran, further investigations are required.

Acknowledgment The authors wish to express their thanks to all participating surgeons and to the research assistants, Mrs. Asgari and Mrs Ghaffari. We also thank Dr Mohsen Valizadeh for his help in editing the manuscript.

Open Access This article is distributed under the terms of the Creative Commons Attribution Noncommercial License which permits any noncommercial use, distribution, and reproduction in any medium, provided the original author(s) and source are credited.

\section{References}

1. Lippuner K, von Overbeck J, Perrelet R et al (1997) Incidence and direct medical costs of hospitalizations due to osteoporotic fractures in Switzerland. Osteoporos Int 7:414-425

2. Wildner M, Clark DE (2001) Hip fracture incidence in east and West Germany: reassessment ten years after unification. Osteoporos Int 12:136-139 
3. Paspati I, Galanos A, Lyritis GP (1998) Hip fracture epidemiology in Greece during 1977-1992. Calcif Tissue Int 62:542-547

4. Finsen V, Johnsen LG, Trano $G$ et al (2004) Hip fracture incidence in central Norway: a follow-up study. Clin Orthop Relat Res 419:173-178

5. Lofthus CM, Osnes EK, Falch JA et al (2001) Epidemiology of hip fractures in Oslo, Norway. Bone 29:413-418

6. Moayyeri A, Soltani A, Larijani B et al (2006) Epidemiology of hip fracture in Iran. Osteoporos Int 17:1252-1257

7. Soveid M, Serati AR, Masoompoor M (2005) Incidence of hip fracture in Shiraz, Iran. Osteoporos Int 16:1412-1416

8. Memon A, Pospula WM, Tantawy AY et al (1998) Incidence of hip fracture in Kuwait. Int J Epidemiol 27:860-865

9. Larijani B, Soltani A, Pajouhi M et al (2003) Bone mineral density variation in 20 to 69 -years-old population of Tehran-Iran (in Persian). Iran South Med J 1:41-49

10. Omrani GR, Masoompour SM, Hamidi A et al (2006) Bone mineral density in the normal Iranian population: a comparison with American reference data. Arch Osteoporos 1:29-35

11. Hashemipour S, Larijani B, Adibi H et al (2004) Vitamin D deficiency and causative factors in the population of Tehran. BMC Public Health 4:38

12. Allander E, Gullberg B, Johnell O et al (1998) Circumstances around the fall in a multinational hip fracture risk study: a diverse pattern for prevention. MEDOS (Mediterranean Osteoporosis) Study Group. Accident Anal Prev 30:607-616

13. Cumming RG, Klineberg RJ (1994) Fall frequency and characteristics and the risk of hip fractures. Am Geriatr Soc 42:774-778

14. Marks R, Allegrante JP, Ronald MacKenzie C et al (2003) Hip fractures among the elderly: causes, consequences and control. Ageing Res Rev 2:57-93

15. Yan L, Crabtree NJ, Reeve J et al (2004) Does hip strength analysis explain the lower incidence of hip fracture in the People's Republic of China? Bone 34:584-588

16. Finsen V, Johnsen LG, Trano G et al (2004) Hip fracture incidence in central Norway: a follow-up study. Clin Orthop Relat Res 419:173-178

17. Melton LJ 3rd, Crowson CS, O'Fallon WM (1999) Fracture incidence in Olmsted County, Minnesota: comparison of urban with rural rates and changes in urban rates over time. Osteoporos Int 9:29-37

18. Ho SC, Bacon WE, Harris T, Looker A et al (1993) Hip fracture rates in Hong Kong and the United States, 1988 through 1989. Am J Public Health 83:694-697
19. Elffors I, Allander E, Kanis JA et al (1994) The variable incidence of hip fracture in Southern Europe: The MEDOS Study. Osteoporos Int 4:253-263

20. Xu L, Lu A, Zhao X et al (1996) Very low rates of hip fracture in Beijing, People's Republic of China the Beijing Osteoporosis Project. Am J Epidemiol 144:901-907

21. El Maghraoui A, Koumba BA, Jroundi I et al (2005) Epidemiology of hip fractures in 2002 in Rabat, Morocco. Osteoporos Int 16:597-602

22. Castro da Rocha FA, Ribeiro AR (2003) Low incidence of hip fractures in an equatorial area. Osteoporos Int 14:496-499

23. Abolhassani F, Moayyeri A, Naghavi M et al (2006) Incidence and characteristics of falls leading to hip fracture in Iranian population. Bone 39:408-413

24. Huo D, Lauderdale DS et al (2003) Influence of reproductive factors on hip fracture risk in Chinese women. Osteoporos Int 14:694-700

25. Cumming RG, Klineberg R (1993) Breastfeeding and other reproductive factors and the risk of hip fracture in elderly women. Int J Epidemiol 22:684-691

26. Kreiger N, Kelsey JL, Holford TR et al (1982) An epidemiologic study of hip fracture in postmenopausal women. Am J Epidemiol 116:141-148

27. Boonyaratavej N, Suriyawongpaisal P, Takkinsatien A et al (2001) Physical activity and risk factors for hip fractures in Thai women. Osteoporos Int 12:244-248

28. Hernández JL, Olmos JM, Alonso MA et al (2006) Trend in hip fracture epidemiology over a 14-year period in a Spanish population. Osteoporos Int 17:464-470

29. Levy AR, Bensimon DR, Mayo NE et al (1998) Inclement weather and the risk of hip fracture. Epidemiology 9:172-177

30. Lin HC, Xiraxagar S (2006) Seasonality of hip fractures and estimates of season-attributable effects: a multivariate ARIMA analysis of population-based data. Osteoporos Int 17:795-806

31. Douglas S, Bunyan A, Chiu KH et al (2000) Seasonal variation of hip fracture at three latitudes. Injury 31:11-19

32. Alvarez-Nebreda ML, Jiménez AB, Rodríguez P et al (2007) Epidemiology of hip fracture in the elderly in Spain. Bone 10:278-285

33. Jiang HX, Majumdar SR, Dick DA et al (2005) Development and initial validation of a risk score for predicting in-hospital and 1 -year mortality in patients with hip fractures. J Bone Miner Res $20: 494-500$ 